\title{
Profile of Malignant Bone Tumors among Rheumatology Inpatients in Lome (Togo)
}

\author{
Kodjo Kakpovi' ${ }^{1}$, Prénam Houzou ${ }^{2}$, Eyram Fianyo ${ }^{3}$, Messanvi Kpoti' \\ Viwalé E. S. Koffi-Tessio', Komi C. Tagbor ${ }^{4}$, Owonayo Oniankitan², Moustafa Mijiyawa1 \\ ${ }^{1}$ Rheumatology Department, CHU Sylvanus, Lomé, Togo \\ ${ }^{2}$ Rheumatology Department, CHU Kara, Kara, Togo \\ ${ }^{3}$ Rheumatology Department, CHR Lomé Commune, Lomé, Togo \\ ${ }^{4}$ Rheumatology Department, Hôpital de Bè, Lomé, Togo \\ Email: kakpovik@yahoo.fr, h_prenam@yahoo.fr, efianyo@gmail.com, annitess2005@gmail.com, \\ tcyrille18@yahoo.ca, Owonayo@yahoo.com,mijiyawa@tg.refer.org
}

Received 27 April 2016; accepted 12 July 2016; published 15 July 2016

Copyright (C) 2016 by authors and Scientific Research Publishing Inc.

This work is licensed under the Creative Commons Attribution International License (CC BY).

http://creativecommons.org/licenses/by/4.0/

(c) (i) Open Access

\section{Abstract}

Background: The reel impact of malignant bone tumors in adults seems unclear in Black Africa. Aim: The aim of this study is to determine the epidemiological and the semiological profile of malignant bone tumors in rheumatology inpatients at Hospital University Center Sylvanus Olympio in Lome. Methods: It was a retrospective study of recorded cases conducted over a period of 19 years in the rheumatology department at Hospital University center Sylvanus Olympio in Lome, Togo. Results: One hundred and sixty-six patients $(68$ women and 98 men) suffered from a bone tumor. The average age of patients was 55 years old with some extremes cases of 14 and 98 years old. The most affected age group was the one between 46 and 55 years old (40 cases, $24.1 \%$ ). The disease's average duration was 17 months. These tumors were primary in 43 cases (26\%) and secondary in $123(74 \%)$. Metastases were those of prostate ( 44 cases, $35.7 \%$ ), breast (12 cases, $9.7 \%$ ), bronchus ( 7 cases, $5.7 \%)$, cervix (5.7\%), and liver ( 2 cases, $1.6 \%)$. Myeloma ( 34 cases; $79.0 \%$ ) and osteosarcoma ( 9 cases; $20.9 \%$ ) were the main primary malignant bone tumors. However, 41 cases $(33.3 \%)$ of malignant bone tumors had not been able to label. The spine was the predilection part for all above-mentioned tumors. Conclusion: This study shows the significant part occupied by malignant bone tumors in musculoskeletal diseases within the sub-Saharan population in general and Togo in particular.

\section{Keywords}

Bone Tumors, Rheumatology, Africa 


\section{Introduction}

Malignant bone tumors are serious and common diseases in occident and in Africa. They are dominated on the one hand by the multiple myeloma which has an annual incidence of 3 to 4 cases for 100,000 populations in the United-States [1], 6.1 for 100,000 populations in the United-Kingdom [2] and 0.4 for 100,000 populations in Algeria [3], and on the other hand by bone metastasis with breast cancer and bronchia-pulmonary in occident [4]; and by cancers of the prostate, breast and liver [5]-[7] in Africa. Severe symptoms such as pain associated with bone lesions, renal failure and pathological fractures can be the first modes of revelation of the disease. Their treatment requires a multidisciplinary approach. Radiation therapy is one of the key resources available to treat bone metastases near all medical or surgical arsenals [8]. In Africa in general, the diagnosis is not always easy and the management remains poor due to lack of resources both technical and financial, and especially access still limited to appropriate health facilities.

In Togo, the reel impact of bone tumors seems unknown. Our study, therefore, aims at determining the epidemiological and semiological profile of malignant bone tumors.

\section{Patients and Methods}

\subsection{Data Source}

It is a study of series of recorded cases implemented between January 1990 and December 2008 in the rheumatology department at the University Hospital Center SYLVANUS OLYMPIO.

\subsection{Patient Selection}

The series included all patients admitted into hospital for a primary or a secondary bone malignant tumor. The study was approved by the ethics committee.

\subsection{Patients' Background Characteristic}

The diagnosis of bone tumor was based on clinical signs, radiological signs, and laboratory tests and even on histology. The socio-demographical, clinical, paraclinical, therapeutic and evolutionary data were collected from their files. Each patient went through a complete blood count, sedimentation rate, electrophoresis of serum proteins, a creatinine, serum calcium and radiography of painful parts. Marrow-bone has been carried out in case of myeloma suspected in front of monoclonal gammopathy objectivized in electrophoresis of serum protein.

\subsection{Definitions of Standard}

Anaemia was the concentration in hemoglobin less than $10 \mathrm{~g} / \mathrm{dl}$. Acreatinine higher than $12 \mathrm{mg} / \mathrm{l}$ was considered as kidney deficiency. Calcemia higher than $110 \mathrm{mg} / \mathrm{l}$ was considered as hypercalcemia. The speed of sedimentation higher than $20 \mathrm{~mm}$ in the first hour was considered as accelerated. The combination of asthenia, anorexia, weight loss (weight loss $>10 \%$ of the previous weight was considered massive) and a clinical pallor or the presence of at least three of these symptoms was considered as general condition impairment.

\subsection{Statistical Analyses}

The statistical analysis of results was performed using Epi info 7.0 software and STATA/IC 11.0.

\section{Results}

Two thousand and eighteen patients were hospitalized from October 1989 to December 2008 in Rheumatology Department of the University Hospital Sylvanus Olympio of Lomé among which 166 (8.2\%) had malignant bone tumors. These 166 patients were divided into 98 men (59\%) and 68 women (41\%). Their average age at admission was 55 years old with some extremes cases of 14 and 98 years old and the most affected age group was the one between 46 and 65 years old (80 cases, 47\%). The disease average duration was 17 months with a clear predilection for that between 2 and 24 months (115 cases, 73\%). These 166 patients were divided into 43 cases (26\%) of primary bone tumors and in 123 cases (74\%) of secondary bone tumors in which 41 cases (33.3\%) of primary tumor have been identified (Table 1). Bone multiple myeloma (34 patients, 79.0\%), bone metastasis 
Table 1. Patient demographics by diagnosis.

\begin{tabular}{cccc}
\hline & Number (\%) & Sex Female/Male & Age at diagnosis $\mathrm{m} \pm \mathrm{ET}^{*}$ \\
\hline Primary bone tumors & $43(25.9)$ & 0.9 & $51.18 \pm 16.12$ \\
Secondary bone Tumors & $123(74.1)$ & 0.6 & $56.27 \pm 14.92$ \\
-determined etiology & $82(66.6)$ & 0.5 & $58.93 \pm 13.61$ \\
-unknown etiology & $41(33.3)$ & 1.05 & $54.35 \pm 20.11$ \\
\hline
\end{tabular}

${ }^{*}$ Mean \pm standard deviation.

of prostate tumor (44 cases, 35.7\%) and probable metastasis (41 cases, 33.3\%) were the main clinical forms of bones malignant tumors (Table 2). The onset of the disease was progressive in 140 patients (84.3\%) and brutal in the26 others $(15.7 \%)$. Inflammatory pain (126 cases, $75.9 \%)$, impairment of the general condition (125cases, 75.3\%), gait (124 cases, 74.7\%), mechanical pain (37 cases, 22.9\%), prostatism signs (30 cases, 18.1\%), the known tumor (18 cases, 10.8\%), bone swelling (14 cases, 8.4\%) and the bleeding exteriorized (5 cases, 3.0\%) were the ways bones tumors expressed in our patients. The spine was the main part of pain (101 cases, 60.84\%) with a clear predilection for the lumbar segment (84 cases, 50.6\%). The pain was also on the dorsal spine (33 cases, 19.8\%), the cervical spine (13 cases, 07.8\%), the long bones (32 cases, 19.3\%) and was diffuse in 37 cases $(22,3 \%)$. The Spinal cord compression was objectivized in 52 patients (31.3\%) and the lymph nodes in 17 (10.2\%). The predominant damage during the abdomen clinical examination of the 166 patients was the hepatomegaly found in isolation in 9 patients, but associated with splenomegaly in 2 . In $81.5 \%$ of cases, the abdomen examination was normal. The radiological damage in 166 patients were bone lysis (76 cases, 45.7\%), the vertebral fracture (64 cases, 38.5\%), the sclerosis (37 cases, 22.2\%), bone diffuse demineralization (34 patients, 20.4\%) and pathologic fracture (9cases, 05.4\%) (Table 3). Biologically and concerning the diagnosis of a lesion, protein electrophoresis showed an evocative monoclonal peak in 22 patients (64.7\%) and marrow bone examination revealed spinal plasmocytose compatible with Kahler's disease in 31 patients (91, 1\%). The specific antigen of the prostate was very high in 31 patients (70.4\%) out of the 44 bone metastasis carriers of prostateneoplasia. Medical treatment was administered to 166 patients involved in our study, while only14 patients (8.4\%) had been eligible for surgical and 12 (7.2\%) for orthopaedic treatment. We recorded 17 (10.2\%) deaths during hospitalization. These 17 deaths were mainly dominated by myeloma (7 cases, $41.2 \%$ ), bone tumors of unknown etiology (4 cases, 23.5\%) and prostate cancer (3 cases, $17.6 \%$ ).

\section{Discussion}

We noted a clear predominance of secondary malignant bone tumors (82 cases, 49.4\%), with patients sex ratio female/male 0.5 and the average age was 56.6 years old. In the group of patients suffering from primarymalignant bone tumors (43 cases, 26\%) the sex ratio female/male was 0.9 and the average age was 46 years old which corresponded to the results obtained by Daboiko et al. in Abidjan who place first bone metastasis [9] and those obtained by Omololu et al. who found in Ibadan in Nigeria only $0.53 \%$ of primary bonemalignant tumors on 114 patients who have presented malignant bone tumors over a period of 23 years [10]. These data reflect the significant incidence of bone metastases compared to primary malignant bone tumors in sub-Saharan Africa. This could also be due to the ease of bone metastasis diagnosis compared to primary malignant bone tumors taking into account the available facilities in sub-Saharan Africa. These results differed from those of Mexico where Baena-Ocampoandal found $18.6 \%$ of bone metastasis against $81.4 \%$ of primary malignant bone tumors [11] and those of Thailand where Settakorn et al. found out of 960 bones tumors identified, 856 (89\%) primary malignancies against 104 (11\%) primary bone metastases [12]. Bahebeck et al. found as well in Cameroon got 6\% of bone metastasis against $45 \%$ of primary malignant bone tumors [5]. These last data would meana greatest access of patients to histological examination necessary for bone tumors diagnosis in general and for primary bone tumors in particular without ignoring patient recruitment criteria.

Out of 166 cases of bone tumors collected over19 years in our study, primary bones malignant tumors were dominated by myeloma (34 cases, 20.5\%) and by osteosarcoma (9 cases, 5.4\%). These results contrast with those of Thailand where Settakorn et al. have found 71 cases of myeloma out of 856 primary bones malignant tumors cases and place it in second position after lymphocytic leukemia (583 cases, 68.1\%) and osteosarcoma 
Table 2. Patient demographics based on the lesion diagnostic.

\begin{tabular}{cccc}
\hline & Number (\%) & Sex Female/Male & Age atdiagnosis (ans) $\mathrm{m}^{\prime} \mathrm{ET}^{*}$ \\
Myeloma & $34(79.0)$ & $15 / 19$ & $54.82 \pm 13.46$ \\
Osteosarcoma & $9(20.9)$ & $5 / 4$ & $37.44 \pm 18.65$ \\
Prostate cancer & $44(35.7)$ & $0 / 44$ & $65.22 \pm 9.25$ \\
Bone tumors of unknown etiology & $41(33.3)$ & $21 / 20$ & $54.35 \pm 20.11$ \\
Breast cancer & $12(9.7)$ & $12 / 0$ & $53.50 \pm 13.76$ \\
Cancer bronchopulmonary & $7(5.7)$ & $1 / 6$ & $51.43 \pm 20.57$ \\
Cervical cancer & $7(5.7)$ & $7 / 0$ & $49.00 \pm 4.62$ \\
Malignant lymphoma & $4(3.2)$ & $3 / 1$ & $38.25 \pm 10.75$ \\
Hépatocarcinoma & $2(1.6)$ & $1 / 1$ & $64.50 \pm 6.36$ \\
Esophageal cancer & $1(0.8)$ & $0 / 1$ & $80.00 \pm 0.00$ \\
\hline
\end{tabular}

*Mean \pm standard deviation.

Table 3. Distribution of patients according to the results of X-ray painful bone segment.

\begin{tabular}{ccc}
\hline & Number & Percentage \\
\hline Bone loss & 76 & 45.7 \\
Vertebral fracture & 64 & 38.5 \\
Sclerosis & 37 & 22.2 \\
Bone diffuse demineralization & 34 & 20.4 \\
Pathologic fracture & 09 & 5.4 \\
Normal & 03 & 1.8 \\
\hline
\end{tabular}

(58 cases 6.7\%) ranked third [12]. In the USA, Weber et al. found a prevalence of osteosarcoma over Ewing's tumors and chondrosarcoma [13]. In Mexico, Baena-Ocampo et al. have found in order of frequency in theprimary malignant bone tumors group, osteosarcoma (46.6\%), chondrosarcoma $(8.7 \%)$ and multiple myeloma bones (8.1\%) [11]. Contrariwise in India, over 5 years Yeole and Jussawalla have found in term of frequency related to the primary malignancies a predominance of Ewing's sarcoma before chondrosarcoma and osteosarcoma came third [14]. In Nigeria, Abdulkareem et al. Lagos found a clear predominance of osteosarcoma over the 77 cases of bone tumors collected [7]. These results confirm the significant incidence of osteosarcoma in black as well in white. However, the weakness of this rate especially in south of the Sahara countries would be related to the deficit in both human and material as well as financial resources in easy diagnosis of this disease.

Eighty-two cases (49.4\%) of bone metastasis were reported at the end of our study out of 166 bone tumors diagnosed over 19 years. Prostate cancer (44 cases, 26.5\%) was the first of primary cancers responsible for bones metastasis followed by breast cancer (12 cases, $7.2 \%$ ) lung cancer and cervical cancer ( 7 cases $4.2 \%$ in each case). These results are in line with those obtained by Oniankitan who noticed over a period of 17 years a clear predominance of bone metastases associated with prostate cancer before those of breast and cervical cancer [15]. Our results were in harmony with those of Côte d'Ivoire from two different studies. It was the one of Kouakou who still found on top prostate cancer but this time followed by hepatocellular carcinoma, kidney cancer, thyroid, lung, breast and anus [16]. Daboiko et al. found a clear predominance of bone metastasis linked to prostate cancer at the Hospital University of Cocody [9].

The results of our study were comparable to those got in Cameroon by Bahebeck et al. who found on top of primary cancers responsible for metastasis, the one of the prostate, followed by breast cancer, hepatocellular carcinoma and thyroid cancer [5]. 
All these results suggest a very great frequency of prostate cancer in blacks than in whites. Whereas in Tunis, Belhaj et al. found 60 cases of bone metastasis, 25 come from breast cancer and 8 from theotorhinolaryngological sphere [17]. In Lille, Vandecandelaere et al. objectivized a predominance of bronchia-pulmonary cancers compared to prostate and breast cancers [18]. These data still confirm the high incidence of prostate cancer in the black compared to white. At the end of our study over 166 cases collected, no cases of bone metastasis from thyroid cancer had been found, which was not much opposed to the results got by Hindié et al. who only found in Paris, 16 cases (1.6\%) of proven bone metastasis out of 961 patients with thyroid cancer who benefited of a total thyroidectomy [19]. This situation would be linked to the fact that this thyroid disease carriers are directed to the Otorhinolaryngology service even at an advanced stage of metastasis, which makes difficult bone metastasis care in rheumatology.

At the end of our study, out of 166 patients enrolled, 41 (24.7\%) had malignant bone tumors which nature had not been exactly elucidated. Their sex ratio female/male was 1.05 with an average age of 54.3 years old in diagnosis. This ratio was up previously in Lome where Oniankitan [15] had gotten 52.3\% of bone tumors which exact nature had not been clarified. The decline in the proportion of unidentified bone tumors is associated with a deepening of both biological and morphological explorations showing a significant progress in rheumatological care at the Hospital University Center Sylvanus-Olympio. In Cameroon, Bahebeck et al. only found 1\% of unknown etiology bone tumors out of 268 cases collected over 10 years [5], probably that situation second a good involvement of patients in care and especially their access to necessary examinations to diagnose these diseases. These taures were much lower than those got in Lille by Vandecandelaere et al. who obtained 38\% of unknown bones tumors type in 1996 against 27\% in 1967 [18].

\section{Conclusion}

Bones metastasis seems more frequent than primary malignant bone tumors which are essentially represented by myeloma and osteosarcoma. The main primary cancers responsible for bones metastasis were prostate, breast, bronchus and cervical cancers.

\section{Conflict of Interest}

None.

\section{References}

[1] Jemal, A., Siegel, R., Tiwari, C., Ghafoor, A., et al. (2004) Cancer Statistics 2004. A Cancer Journal for Clinicians, 54, 8-29. http://dx.doi.org/10.3322/canjclin.54.1.8

[2] Cancer Statistics for the UK. http://info.cancerresearchuk.org/cancerstats

[3] Virk, M.S. and Lieberman, J.R. (2007) Tumor Metastasis to Bone. Arthritis Research and Therapy, 9, S5. http://dx.doi.org/10.1186/ar2169

[4] Gremaud, M., Delouche, D. and Monnerat, C. (2006) Treatment of Bone Metastases with Bisphosphonates. Revue médicale Suisse, 75, 1861-1866.

[5] Bahebeck, J., Atangana, R., Eyenga, V., Pisoh, A., Sandoz, Z. and Hoffmeyer, P. (2003) Bones Tumors in Cameroon: Incidence, Demography and Histopathology. International Orthopaedics, 27, 315-317. http://dx.doi.org/10.1007/s00264-003-0480-7

[6] Sarma, N.H., Al-fituri, O., Visweswara, R.N. and Saeed, S.O. (1994) Primary Bone Tumor in Eastern Libya, a 10-Year Study. Central African Journal of Medicine, 40, 418-451.

[7] Abdulkareem, F.B., Evesan, S.U., Akinde, O.R., Ezembakwe, M.E. and Nnodu, E. (2007) Pathological Studies of Bone Tumors at the National Orthopaedic Hospital. West African Journal of Medicine, 26, 306-311.

[8] Lagrange, J.L., Pan, C., Calitchi, E., Diana, C., Muresan, M., Wu, J.F., et al. (2008) Practical Radiation Therapy for Painful Bone Metastases. Revue Du Rhumatisme, 75, 530-535. http://dx.doi.org/10.1016/j.rhum.2008.02.005

[9] Daboiko, J.C., Eti, E., Yapi, I., Ouali, B., Ouattara, B. and N’zué, K. (2004) Inflammatory Rheumatic Diseases at Cocody University Medical Center (Abidjan) from March 1998 to March 2000. Joint Bone Spine, 71, 598-599. http://dx.doi.org/10.1016/j.jbspin.2004.04.011

[10] Omololu, A.B., Ogunbivi, J.O., Ogunlade, S.O., Alonge, T.O., Adebisi, A. and Akang, E.E. (2002) Primary Malignant Bone Tumors in a Tropical African University Teaching Hospital. West African Journal of Medicine, 21, 291-293. 
[11] Baena-Ocampo, C., Atangana, R., Eyenga, V., Pisoh, A., Sandoz, Z. and Hoffmeyer, P. (2009) Epidemiology of Bones Tumors in Mexico City: retrospective Clinicopathologic Study of 566 Patients at a Referral Institution. Annals of Diagnostic Pathology, 13, 16-21. http://dx.doi.org/10.1016/j.anndiagpath.2008.07.005

[12] Settakorn, J., Lekawanvijit, S., Arpornchayanon, O., Rangdaeng, S., Vanitanakom, P., Kongkarnka, S., et al. (2006) Spectrum of Bones Tumors in Chiang Mai University Hospital, Thailand According to WHO Classification 2002: A Study of 1001 Cases. Journal of Medical Association of Thailand, 89, 780-787.

[13] Weber, K., Damron, T.A., Frassica, F.J. and Sim, F.H. (2008) Malignant Bones Tumors. Instructional Course Lectures, 57, 673-88.

[14] Yeole, B.B. and Jussawalla, D.J. (1998) Descriptive Epidemiology of Bone Cancer in Greater Bombay. Indian Journal Cancer, 35, 101-106.

[15] Oniankitan, O., Houzou, P., Kakpovi, K., Koffi-Tessio, V., Tagbor, K.C., Fianyo, E. and Mijiyawa, M. (2013) Rheumatic Diseases Profile of 13517 West African Patients. Tunisie Médicale, 91, 16-20.

[16] Kouakoué, N. (1994) Bone Metastasis in Ivory Coast Hospital. Rhumatologie (Aix-les-Bains) A, 46, $243-245$.

[17] Belhaj, R., Boussen, H., Ghanem, A. and Essafer, S. (2002) Bioclinical Correlations in Bony Metastases. Results of a Prospective Study. 60 Cases. Tunisie Médicale, 80, 691-695.

[18] Vandecandelaere, M., Flipo, R.-M., Cortet, B., Catanzariti, L., Dusquenoy, B. and Delcambre, B. (2004) Bone Metastases Revealing: A Comparative Study 30 Years Apart. Joint Bone Spine, 71, 390-396.

[19] Hindié, E., Zanotti-Fregonara, P., Keller, I., Duron, F., et al. (2007) Bone Metastases of Differentiated Thyroid Cancer: Impact of Early ${ }^{131}$ I-Based Detection on Outcome. Endocrine-Related Cancer, 14, 799-807. http://dx.doi.org/10.1677/ERC-07-0120

\section{Submit or recommend next manuscript to SCIRP and we will provide best service for you:}

Accepting pre-submission inquiries through Email, Facebook, LinkedIn, Twitter, etc.

A wide selection of journals (inclusive of 9 subjects, more than 200 journals)

Providing 24-hour high-quality service

User-friendly online submission system

Fair and swift peer-review system

Efficient typesetting and proofreading procedure

Display of the result of downloads and visits, as well as the number of cited articles

Maximum dissemination of your research work

Submit your manuscript at: http://papersubmission.scirp.org/ 